Geopolítica(s) Revista de estudios sobre espacio y poder ISSN: 2172-3958

\title{
La inexistente respuesta regional a la COVID-19 en América Latina ${ }^{1}$
}

\author{
Jerónimo Ríos Sierra²
}

Recibido: 7 de mayo de 2020 / Aceptado: 10 de mayo de 2020

Resumen. América Latina afronta la situación de pandemia ocasionada por la COVID-19 desprovista de espacios regionales de consenso y cooperación. El fin de un ciclo expansivo de la economía, sumado a una estructura social maltrecha, con necesidades acuciantes irresolutas, no representa el mejor escenario para hacer frente a la situación de alerta sanitaria. El objetivo de este trabajo es reflexionar sobre estos aspectos, alertando de la inexistencia de una arquitectura regional sólida y sus consecuencias. Para ello, se revisan todos los esquemas regionales del continente y se analiza la manera en la cual se han dispuesto espacios multilaterales para la toma conjunta de decisiones. Así, con la excepción del Sistema de Integración Centroamericano y la Organización Panamericana de Salud, apenas es posible encontrar compromisos regionales más allá del intercambio de información o la preocupación por la reactivación económica.

Palabras clave: pandemia de COVID-19; América Latina; geopolítica; integración regional; Organización Panamericana de Salud.

\section{[en] The Non-existent Regional Response to COVID-19 in Latin America}

\begin{abstract}
Latin America is facing the pandemic situation caused by COVID-19 devoid of regional spaces for consensus and cooperation. The end of an expansionary cycle of the economy, added to a very weak social structure, with unresolved pressing needs, does not represent the best scenario to confront the health alert situation. The objective of this work is to reflect on these aspects, warning of the absence of a solid regional architecture and its consequences. For this, the work reviews all the regional schemes of the continent and analyzes the way in which multilateral spaces have been arranged for joint decision-making. Thus, except for the Central American Integration System and the Pan American Health Organization, it is scarcely possible to find regional commitments beyond the exchange of information or concern about economic recovery.

Keywords: COVID-19 pandemic; Latin America; geopolitics; regional integration; Pan American Health Organization.

\section{[pt] A resposta regional inexistente à COVID-19 na América Latina}

Resumo. A América Latina enfrenta a situação de pandemia causada pela COVID-19, desprovida de espaços regionais para o consenso e a cooperação. O fim de um ciclo expansionista da economia,

1 Este trabajo de investigación se inscribe en el proyecto 2018-T2/SOC-10508.

2 Investigador postdoctoral en la Facultad de Ciencias Políticas y Sociología de la Universidad Complutense de Madrid, como beneficiario de las Ayudas de Atracción del Talento Investigador que cofinancia la Comunidad de Madrid (2018).

E-mail: jeronimo.rios@ucm.es
\end{abstract}


somado a uma estrutura social desgastada, com necessidades prementes não resolvidas, não representa o melhor cenário para enfrentar a situação de alerta sanitária. O objetivo deste trabalho é refletir sobre esses aspectos, alertando para a inexistência de uma arquitetura regional sólida e suas consequências. Para isso, todos os esquemas regionais do continente são revistos e a maneira pela qual os espaços multilaterais foram organizados para a tomada de decisões conjunta é analisada. Assim, com exceção do Sistema de Integração Centro-Americano e da Organização Pan-Americana da Saúde, praticamente não foram encontrados compromissos regionais, para além da troca de informações ou a preocupação com a recuperação econômica.

Palavras-chave: pandemia da COVID-19; América Latina; geopolítica; integração regional; Organização Pan-Americana da Saúde.

Sumario. Introducción. 1. Debilidades estructurales de América Latina frente a la COVID-19. 2. Respuestas estatales sin un criterio definido. 3. Una respuesta regional que brilla por su ausencia. 3.1. Comunidad Andina y Alianza del Pacífico. 3.2. Mercosur. 3.3. El Sistema de Integración Centroamericano. 3.4. El regionalismo posliberal: ALBA, UNASUR y CELAC. 3.5. La respuesta interamericana: OEA y OPS. Conclusiones. Referencias.

Cómo citar: Ríos Sierra, J. (2020). La inexistente respuesta regional a la COVID-19 en América Latina. Geopolítica(s). Revista de estudios sobre espacio y poder, 11(Especial), 209-222.

\section{Introducción}

El impacto de la pandemia ocasionada por la COVID-19 está situado en el centro de las miradas de buena parte del mundo. Desde las ciencias sociales en particular se está tratando de entender, por ejemplo, cómo la COVID-19 puede redefinir las relaciones entre el Estado, el Mercado y la sociedad civil (McKibbin y Fernando, 2020; Allen et al., 2020). Asimismo, se trata de vislumbrar cómo será su impacto asimétrico entre las diferentes regiones del planeta (Baldwin y Weder, 2020; Gilbert et al., 2020). Mientras, otras lecturas alertan sobre algunas de sus consecuencias, tal y como sucede con el discurso nacionalista que resignifica la identidad nacional y se articula entre las categorías excluyentes "ellos" y "nosotros" o "vencedores" y "vencidos" (Flynn, 2020; Maxwell et al., 2020).

A tal efecto, la mirada espacial y situada de la geografía política (Cairo, 2013), tiene mucho que aportar, especialmente, si se tiene en consideración la transnacionalidad que representa esta amenaza (Beck, 1992) y, a su vez, las tensiones multiescalares que ocasiona (Taylor y Flint, 2006). Y es que, si algo pone de manifiesto, prima facie, esta situación de alerta sanitaria es precisamente la complejidad y la profundidad de las relaciones globales. De hecho, es como si el debate iniciado a principios de los noventa sobre la globalización retornase de manera imperativa a la actualidad (Marsh et al., 2006). De un lado, los hiperglobalistas, eufóricos por entender que esta situación es la perfecta muestra del fin de la geografía y la debilidad fronteriza de los Estados (Reich, 1991; Ohmae, 2005). De otro, los escépticos (Hirst y Thompson, 1999; Rugman, 2000), deseosos por hacer valer de qué modo, el Estado-nación vuelve a estar en el centro del tablero geopolítico. Incluso, cabrían terceras posiciones como la de Hoogvel (1997) o Mann (2002), para quienes el alcance y el impacto de la pandemia refleja cómo, en realidad, la globalización se condensa mayormente sobre tres escenarios: Norteamérica, Europa Occidental y Asia Oriental. 
Retomando una cuestión que planteaba Guerra-Borges (2004) hace algunos años, resulta necesario observar igualmente cómo opera el plano regional en la dimensión interméstica de la amenaza pandémica. De este modo, la heterogeneidad de escenarios demanda de análisis precisos y muy delimitados en cuanto a su enfoque. Por ejemplo, en el caso de la Unión Europea, fruto de las camisas de fuerza que sustantivan el proceso integrador, el margen de maniobra para ciertas cuestiones de la agenda pública pasa necesariamente por la construcción de consensos entre los Estados miembros. Consensos que parecen difíciles cada vez que la Unión tiene ante sí una situación de calado. Primero, por las tensiones entre los intereses del Norte y del Sur, por razones estrictamente económicas, y a su vez, por las desencadenadas entre el bloque occidental y el espacio postsoviético, fruto de cuestiones mayormente nacional-soberanas.

Dicho lo anterior, el objetivo fundamental de este trabajo se centra en América Latina y, concretamente, busca analizar la manera en la que el continente afronta la pandemia sanitaria, enfatizando así en sus diferentes esquemas de integración regional. Para ello, primero se contextualiza la realidad social y económica latinoamericana que ha de hacer frente a la crisis. Después, se presentan a grandes rasgos las reacciones adoptadas por los Estados y, finalmente, se ahonda en cómo los esquemas de integración propios del nuevo regionalismo, del regionalismo posliberal y del proyecto interamericano han planteado respuestas colectivas para hacer frente a esta situación. El resultado es el de un contexto de desencuentro y atomización que, salvo excepciones, cuestiona la esencia misma del proceso integrador latinoamericano.

\section{Debilidades estructurales de América Latina frente a la COVID-19}

La necesidad de disponer de Estados fuertes goza de una alta demanda entre las sociedades latinoamericanas (Cairo y Ríos, 2020). En buena medida, ello se puede observar cuando, cada año, el Latinobarómetro muestra de qué modo la inseguridad se erige como la principal preocupación para los ciudadanos del continente. Además de por la concurrencia de otros factores, de ahí viene el hecho de que tanto gobiernos progresistas como conservadores, recurran al empleo de las Fuerzas Militares para gestionar aspectos relacionados con la seguridad ciudadana.

La actual crisis pandémica acontece bajo un contexto en donde impera un lenguaje bélico, de "guerra contra el coronavirus", y que abre una ventana de oportunidad para que, tras el lenguaje epopéyico de dirigir todos los esfuerzos del Estado contra la COVID-19, se exacerbe el discurso nacionalista y se favorezca un escenario idóneo para medidas de carácter autoritario. A tal efecto, resultan ilustrativas las palabras del presidente chileno Sebastián Piñera, quien agradecía el 11 de abril de 2020 el papel de las Fuerzas Militares, dado que "han protegido las fronteras para que los inmigrantes no traigan la infección" (Cambio 21, 2020).

Lo cierto es que el Estado fuerte latinoamericano tiene "pies de barro" en lo que respecta a su dimensión social, y no corren buenos tiempos para él, pues, como advertía la CEPAL (2020a), la economía de la región se encontraba, antes de la alerta sanitaria, en pleno proceso de estancamiento. Esto, a todas luces, se verá agudizado por el impacto de la COVID-19, no siendo el mejor escenario un merca- 
do profundamente reprimarizado, al que se suma una muy importante caída de los precios de las commodities.

Más compleja si cabe resulta la realidad expuesta, si se tiene en consideración un panorama social como el actual, profundamente excluyente, que, tras un ciclo expansivo de la economía, mantiene irresolutas buena parte de sus fracturas sociales. En la actualidad se contabilizan 190 millones de personas pobres en el continente, y de éstas, se estima que una tercera parte se encuentran en situaciones de pobreza extrema (CEPAL, 2020a). De hecho, la misma CEPAL (2020b) ha alertado cómo la COVID-19 puede dejar consigo en la región un impacto negativo que se traduce en 12 millones de nuevos desempleados y 30 millones de nuevos pobres.

Asimismo, la endeble presión fiscal del Estado (CEPAL, 2020a), la acuciante corrupción (International Transparency, 2020) o la debilidad institucional endémica de sus sistemas democráticos (Freedom House, 2020) se suman a una situación en donde el 53\% de las personas están en situación de informalidad laboral (CEPAL, 2020b). De esta manera, la realidad se torna especialmente preocupante si también se tiene en cuenta que el gasto sanitario apenas llega, en promedio, al $3 \%$ del PIB - muy alejado del mínimo necesario del 6\% que considera la OPS (2017) — . Todo lo anterior, se inscribe en un modelo privatizado, cuando no externalizado, en donde el ciudadano ha sido suplantado en términos clientelares, como consumidor de un servicio, y frente al cual una de cada tres personas no tiene acceso a los servicios básicos sanitarios (OPS, 2020).

Finalmente, queda señalar que todo lo expuesto llega en un momento de elevada conflictividad social, tal y como dan cuenta los recientes casos de Chile, Colombia o Ecuador. No cabe esperar que esta situación amaine, sino que, todo lo contrario, una vez que se supere la alerta sanitaria, el modo en que haya sido gestionada se integre como otro elemento más de disputa. Al margen de estas dificultades, esta particular situación debiera servir para alertar sobre la necesidad de recomponer el trinomio Estado/Mercado/Sociedad desde términos más inclusivos y simétricos. Pero igualmente es momento de poner en valor hasta qué punto resulta necesario en América Latina un escenario de convergencia regional que incluso, en términos más globales, repiense el sentido y la relevancia de la ayuda humanitaria, la cooperación internacional o el papel de la arquitectura financiera internacional, vistas las situaciones de países como Haití o Venezuela, entre otros.

Sin embargo y como se verá a continuación, una respuesta regional — tan necesaria como complementaria a la agenda estatal - hasta el momento brilla por su ausencia. La fractura de esquemas regionales, la preponderancia de las agendas comerciales, la multiplicidad de intereses contrapuestos y el recurso obstinado de reducir cualquier atisbo de respuesta a la escala estrictamente estatal, ponen de manifiesto hasta qué punto la arquitectura regional latinoamericana no pasa en la actualidad por su mejor momento.

\section{Respuestas estatales sin un criterio definido}

La situación de alerta sanitaria llega a la región a comienzos del mes de marzo de 2020, a las pocas semanas de haberse producido el salto de Asia a Europa. A tal efecto, las respuestas gubernamentales han estado mayormente desprovistas de cualquier tipo de acervo regional y se pueden observar una pluralidad de reaccio- 
nes, que van desde los confinamientos severos hasta las posiciones incluso negacionistas. Es cierto que las primeras de ellas han primado, como ha sucedido en Argentina, Bolivia, Colombia, El Salvador, Honduras, Panamá, Perú o Venezuela, que optaron por medidas estrictas desde el principio. No obstante, menos restrictivas fueron las respuestas de Chile, Ecuador, Guatemala, Paraguay, República Dominicana y Uruguay (Malamud y Núñez, 2020). Los casos de Brasil, México o Nicaragua se enmarcarían en el plano de las reacciones erráticas y tardías, cuando no contradictorias, llegando a cuestionar el alcance y la magnitud de la propia pandemia.

El criterio para adoptar unas posiciones $u$ otras ha gravitado en torno al binomio, en muchos casos desafortunadamente planteado, economía versus salud. Es decir, se simplifica la realidad de la amenaza a una ecuación excluyente y mal formulada: más confinamiento sanitario es sinónimo de mayor parálisis de la economía. Todo lo contrario, la salud es una condición imprescindible para que exista reactivación económica, de modo que quienes no lo han entendido así, como Donald Trump en Estados Unidos o Boris Johnson en Reino Unido, hoy tienen ante sí los niveles de escalamiento del contagio más elevados del mundo.

Bolsonaro, asumiendo una posición muy parecida a la inicial de Donald Trump, trató de evitar desde el inicio que cualquier medida sanitaria interfiriese en la normalidad económica de Brasil. De esta manera, el día 25 de marzo, y cuando en el país se contabilizaban más de 2.000 contagios, el presidente brasilero afirmaba que "la vida debe seguir (...) los empleados tienen que ser mantenidos (...) ingreso de las familias tiene que ser preservado" (Público, 2020).

En unos términos muy similares se presentaba un día antes, el 24 de marzo, el presidente mexicano, Andrés Manuel López Obrador. En ese momento el país tenía 300 casos confirmados - con una disposición de camas de cuidados intensivos que apenas llega a 4.000 para atender a una población de 126 millones-y el mandatario alentaba al consumo, llamando a relativizar la importancia de la pandemia: "Yo les voy a decir cuándo no salgan, pero sigan llevando a la familia a comer a las fondas porque eso es fortalecer la economía familiar y popular" (Infobae, 2020).

Por último, en Nicaragua, el Gobierno sandinista encabezado por Daniel Ortega y Rosario Murillo, recurriendo a un título clásico de la obra de García Márquez, impulsaban una marcha multitudinaria bajo el lema: "Amor en tiempos de COVID19". Ello aun cuando el Ministerio de Salud había afirmado en esos días cómo el potencial contagio de COVID-19 podría alcanzar los 30.000 afectados en el país.

Habrá que esperar para observar de qué manera este personalismo errático de Bolsonaro o López Obrador puede socavar su popularidad frente a la opinión pública, y de qué modo pueden aflorar tensiones entre los diferentes niveles gobierno. No debe obviarse cómo Sao Paulo o Ciudad de México, en tanto que son escalas geográficas más expuestas a los riesgos de la amenaza, terminaron tomando decisiones que, en muchas ocasiones, iban por derroteros claramente opuestos a los planteados por el nivel de autoridad central.

\section{Una respuesta regional que brilla por su ausencia}

Desde el plano estrictamente regional, las posibilidades de coordinación y convergencia y la adopción de decisiones planteadas desde el multilateralismo, más allá 
de excepciones y matices, como se señalaba, han brillado por su ausencia. En términos generales, las razones no soy muy diferentes a las que explican la debilidad regional latinoamericana lato sensu. Es decir, la construcción de códigos geopolíticos unilaterales, la multiplicidad de estructuras regionales, en muchas ocasiones, contradictorias entre sí, las carencias en cuanto a mecanismos de confianza mutua, así como las resistencias a cualquier atisbo de supranacionalidad regional, pueden evocarse como explicativas de lo anterior (Malamud, 2009; Serbin, 2009; Ríos, 2011; Cairo y Ríos, 2018). Además, si a ello se añade un tablero geopolítico fracturado por la ultraderecha populista, con Brasil a la cabeza, y una ausencia de liderazgo regional, más allá de la tímida posición que enarbola el presidente argentino, queda difícil encontrar un acervo regional desde el que dar asidero a la gestión de la pandemia sanitaria en el continente.

Cuestión aparte, otro elemento a destacar es la prevalencia de esquemas regionales de cooperación comercial, como mayormente son los acontecidos bajo el regionalismo abierto de inicios de los 1990. Así, y con la excepción del Sistema de Integración Centroamericano, en la Comunidad Andina y en Mercosur, la principal prioridad, como con posterioridad igualmente ha caracterizado a la Alianza del Pacífico, priman los objetivos centrados en el aperturismo y la liberalización comercial, y en una agenda más comercial que política.

\subsection{Comunidad Andina y Alianza del Pacífico}

La región que muestra una menor articulación regional es la Comunidad Andina, en donde ha predominado el énfasis en retornar, en cuanto sea posible, a los escenarios de dinamismo e intercambio comercial previos a la crisis. Así lo reconocía el Secretario General, el colombiano Jorge Hernando Pedraza, cuando en una nota de prensa del 13 de abril apuntaba lo siguiente:

Las actuales circunstancias exigen un trabajo coordinado entre los países andinos para controlar la pandemia, mantener el comercio regional, reactivar las economías y sostener el empleo (...) Hay que volver a prender el motor de la economía, una vez reparado, para llevar a la prosperidad a los 111 millones de ciudadanos andinos. (Secretaría General de la Comunidad Andina, 2020).

Lo cierto es que los instrumentos para avanzar y dotarse de mecanismos regionales para hacer frente a la pandemia han brillado por su ausencia. Algo que en cierta manera refleja el proceso de decadencia acuciante que viene experimentado, desde 2006, este proceso de integración (Acosta, 2006). Colombia y Perú, por un lado, mantienen, junto a México y Chile, las posiciones más unilaterales del continente, inspiradas en una ausencia notable de compromisos regionales. Baste recordar al efecto que fueron los países que se desmarcaron del escenario andino para negociar tratados de libre comercio tanto con Estados Unidos como con la Unión Europea (Sanahuja, 2013). Ecuador ha dado un giro de $180^{\circ}$ en su política regional, de manera que Lenín Moreno ha abandonado la apuesta integradora que abanderó su predecesor, Rafael Correa, y Bolivia es hoy por hoy un escenario de absoluta incertidumbre tras el golpe de estado producido contra el gobierno de Evo Morales.

Los mayores compromisos quedaron recogidos en la Declaración de Ministros de Relaciones Exteriores y Comercio Exterior de la Comunidad Andina, la cual 
tuvo lugar el 8 de abril. En ella, y más allá de recoger los formalismos sobre la preocupación que ocasiona la pandemia, apenas se concretaron medidas. Cuestión aparte de la recurrida necesidad por afianzar la integración andina y fortalecer los mecanismos sanitarios y la arquitectura institucional, apenas se aprecian tres medidas, a todas luces insuficientes: i) el compromiso por intercambiar en tiempo real la mayor información epidemiológica posible; ii) la promoción de mecanismos de cooperación técnica no reembolsable, aunque siempre de forma bilateral, con la Corporación Andina de Fomento; y iii) el mantenimiento de reuniones virtuales para que, "de estimarse necesario", se coordinen acciones en áreas de interés regional (Comunidad Andina, 2020).

No cabría esperar mucho más de parte de la Alianza del Pacífico, que, si bien es un esquema de integración regional muy reciente, gravita en torno a dos elementos igualmente presentes en la Comunidad Andina. De una parte, la importante resistencia a la supranacionalidad, en tanto que está conformada por los cuatro países que, posiblemente, menos compromisos multilaterales tienen en la región y, asimismo, una agenda que gravita, estrictamente, en torno a cuestiones comerciales (Díaz Galán, 2015). Dadas las circunstancias, los dos protocolos promovidos desde CELAC y que han entrado en vigor en el mes de abril tienen como propósito: i) levantar las limitaciones comerciales para incentivar el intercambio de bienes médico-sanitarios y otros productos con vistas al futuro, y ii) promover la integración tecnológica y el impulso de las telecomunicaciones, previendo un escenario de libre intercambio tecnológico.

\subsection{Mercosur}

En el caso de Mercosur, los avances regionales no son muy diferentes a los acontecidos en el escenario andino. El 18 de marzo de 2020 se celebraba una primera reunión de Jefes de Estado y de Gobierno, a partir de la cual, los cuatro países que conforman la integración mercosureña se comprometían a intercambiar estadísticas sobre el virus, garantizando el movimiento de mercancías y abogando por la necesidad abordar medidas fronterizas.

En unos términos muy similares a los de la Comunidad Andina, se hacía énfasis en la necesidad de buscar instrumentos de financiación provenientes de la Corporación Andina de Fomento o del Banco Interamericano de Desarrollo, dada la preocupación de los dirigentes de la región por experimentar una ralentización en su economía, y que obliga a posponer los procesos actuales de negociación de Tratados de Libre Comercio con la Unión Europa, Corea del Sur, Canadá o Singapur (Mercosur, 2020). De hecho, en ese momento Bolsonaro mantuvo una posición clara en cuanto a priorizar el dinamismo económico y comercial, en tanto que Brasil era el único país que no había cerrado las fronteras y seguía tildando la situación de pandemia como una cuestión de "ficción" o "fantasía".

Unos días después, el 5 de abril, el seno de Mercosur aprobaba un fondo de emergencia para la pandemia de 16 millones de dólares, a cargo del Fondo de Convergencia Estructural, y cuyas prioridades eran la adquisición de material de testeo y el apoyo al eje "Investigación, Educación y Biotecnología aplicadas a la Salud", centrado en exclusiva en cuestiones que atañen a la COVID-19. Finalmente, en la reunión de presidentes del 21 de abril, el Mercosur ratificaba compromisos de mínimos, como son el intercambio de información epidemiológica, de medidas fron- 
terizas como la reducción de aranceles a los bienes sanitarios relacionados con la pandemia o la consecución de líneas de acción conjunta de parte de organismos multilaterales de crédito.

De esta manera, y como se apuntaba también para el escenario andino, no se aprecian grandes compromisos ni dinámicas de convergencia regional en Mercosur. Menos, dada la confluencia de dos códigos geopolíticos sobre la región claramente disímiles como son el de Argentina y el de Brasil. Si bien Alberto Fernández, en estas semanas, ha enfatizado no en pocas ocasiones la necesidad de disponer de un escenario regional de convergencia, que articule mínimos comunes denominadores, la ultraderecha populista que representa Brasil, y que puede contagiar a otros vecinos de la región, transcurre por senderos opuestos. De forma similar a Trump, Bolsonaro reescribe el código geopolítico hacia el continente, en términos de unilateralismo y distanciamiento con los compromisos internacionales. Todo ello hace parte de una política sobrevenida, oscilante y arbitraria, en donde el plano regional es instrumentalizado en favor de "salvaguardar" el interés nacional y la posición preeminente de Brasil, en oposición, tanto a América Latina como a organizaciones internacionales como la OMS (Ríos, 2020).

\subsection{El Sistema de Integración Centroamericano}

Como tradicionalmente ha sucedido en el universo de esquemas subregionales de integración, el modelo centroamericano parece ser el más avanzando de todos, y quizá, es por lo anterior que su respuesta ha sido la más sólida en lo que a términos supraestatales se refiere. Lo anterior puede deberse a que la integración centroamericana se remonta a la Organización de Estados Centroamericanos de 1954, pero también a que existe una mayor dependencia recíproca de sus intereses, una mayor homogeneidad de las necesidades y una mejor interpretación de lo que representa y exige un proceso de integración regional. Tal vez, por esto, es la única región del mundo que, hasta el momento, tiene un Acuerdo de Asociación Estratégica firmado, y en funcionamiento, con la Unión Europea (Ríos, 2013).

Con base en lo anterior, es posible encontrar, por tanto, un nivel de articulación mayor, igualmente favorecido, por una arquitectura institucional más sólida y plural. Antes que ningún otro espacio regional, el 12 de marzo de 2020, los presidentes de los ocho países que conforman el Sistema de Integración Centroamericano impulsaban la declaración "Centroamérica unida contra el Coronavirus". Ésta comprometía un plan de contingencia regional que nada tiene que ver con lo conseguido, ni en el escenario andino ni en el mercosureño. De este modo se comprometían hasta 1.900 millones de dólares con los que prevenir, contener y superar, en clave regional, los efectos de la pandemia. Lo anterior, en torno a tres ejes centrales y dos transversales. Como ejes centrales: i) salud y gestión del riesgo; ii) comercio y finanzas, y iii) seguridad, justicia y migración. Como ejes transversales: i) comunicación estratégica, y ii) gestión de la cooperación internacional (Sistema de Integración Centroamericano, 2020)

De hecho, tan solo dos semanas después, el programa se encontraba en pleno proceso de implementación, toda vez que se han añadido otras acciones, como es el caso de la negociación conjunta para la compra de insumos médicos, la creación de un corredor humanitario centroamericano, un mecanismo regional de asistencia humanitaria o un sistema integrado de indicadores económicos regionales. Igual- 
mente, cabría destacar la conformación de un fondo de emergencia adicional, por valor de ocho millones de dólares, y por el que cada país dispondrá de un millón de dólares para hacer frente a situaciones sobrevenidas por la COVID-19.

\subsection{EI regionalismo posliberal: ALBA, UNASUR y CELAC}

La arquitectura del regionalismo posliberal (Da Motta y Ríos, 2007) se construyó a lo largo de la década del 2000, aprovechando el vacío de poder de Estados Unidos, centrado en la agenda securitaria sobre Oriente Medio (Cairo, 2018), un importante giro a la izquierda, encabezado por Venezuela y Brasil, y un proceso expansivo favorecido por el auge del precio de las commodities. De allí surgieron iniciativas de muy diverso alcance y significado, como la Alternativa Bolivariana para los Pueblos de Nuestra América (ALBA), la Unión de Naciones Suramericanas (UNASUR) y más recientemente, la Comunidad de Estados Latinoamericanos y Caribeños (CELAC). Sin embargo, aun por distintas razones, ninguna pareciera dar visos de ofrecer escenarios sólidos de articulación regional.

En el caso de las dos primeras, por razones obvias, marcadas por la profunda crisis institucional que atraviesan. En el caso de ALBA, inicialmente se concebía como un mecanismo de petrodiplomacia diseñado por Hugo Chávez para conseguir un alineamiento geopolítico con Cuba y algunos países caribeños, además de Nicaragua, Ecuador, Bolivia y Argentina. De aquel proyecto poco queda, dada la situación económica que atraviesa su principal valedor. Ninguno de esos países mantiene su posición de Estados miembros, a excepción de Cuba y Nicaragua, y a los que se suman Antigua y Barbuda, Dominica, Granada, San Cristóbal y Nieves y San Vicente y Granadinas. Así, su papel ha terminado siendo testimonial, tal y como se pudo observar en su última XVIII Cumbre, celebrada en La Habana, en diciembre de 2019.

UNASUR habría sido el escenario idóneo desde el que abordar respuestas colectivas, en clave regional, frente a la amenaza de la COVID-19 si no fuera porque este esquema de integración regional está al borde del abandono. Conviene recordar que, en abril de 2018, seis países miembros, del total de doce, suspendieron temporalmente su vinculación: Argentina, Brasil, Chile, Colombia, Paraguay y Perú. Estos, con el paso de los meses fueron ratificando su abandono y, por si fuera poco, dos más, Ecuador y Uruguay, lo han hecho en el mes de marzo de 2020, durante la alerta sanitaria, arguyendo la marcada impronta de izquierdas de UNASUR. Una razón que muestra el nivel de ideologización de la política regional, la falta de un acervo común que se articule sobre políticas de Estado y no de Gobierno, y que obvia que, en el fondo, los esquemas de integración no son los que adoptan un color u otro sino el alcance y el significado de los gobiernos que los conforman, así como su nivel de compromiso. Por el momento, este esquema mantiene la permanencia de Venezuela, Bolivia, Surinam y Guyana, si bien representa otro fracaso más de la arquitectura regional latinoamericana, evidente cuando ésta se orienta hacia escenarios que no son los estrictamente comerciales (Ríos, 2017).

El único operativo y vigente de estos esquemas sería CELAC, aunque igualmente, se trata del que menos compromisos comporta, habida cuenta de que, stricto sensu, es un proceso de concertación regional y no de cooperación intergubernamental, como todos los anteriores. Es decir, sus posiciones son muy generalistas e imprecisas y en el marco de la alerta sanitaria, verdaderamente, ha servido de muy 
poco. Lo máximo que ha contribuido CELAC ha sido en la creación de diferentes encuentros entre virólogos de la región, lo cual ha terminado por constituir la Red de Expertos en Agentes Infecciosos y Enfermedades Emergentes y Reemergentes. También se han desarrollado alianzas estratégicas con la CEPAL o con la FAO a efectos de complementar estrategias regionales posibles frente a la COVID-19, y que han derivado en la creación de algunos estudios técnicos en materia de desigualdad social o pobreza alimentaria. Finalmente, con CLASCO se habría concertado la elaboración de un informe regional que dé cuenta de cómo el virus ha impactado en el continente latinoamericano en materia de género, etnia o territorio, poniendo de manifiesto que la dimensión de sus acciones transita por un plano de mucha mayor "superficialidad".

\subsection{La respuesta interamericana: OEA y OPS}

En todo el elenco de escenarios y posibilidades regionales analizadas, no se puede dejar por fuera la propuesta proveniente del regionalismo de impronta interamericana. En lo que tiene que ver con la OEA, desde hace años, si no décadas, el proyecto hemisférico no pasa por su mejor momento. Es cierto que durante el segundo mandato de Barack Obama se trató de impulsar el andamiaje interamericano, especialmente, una vez que la presencia en Irak y Afganistán se desdibujaba y el ciclo progresista ofrecía visos de agotamiento. Empero, la llegada de Donald Trump a la Casa Blanca cercenó cualquier posibilidad al respecto.

No deja de sorprender que, en plena alerta sanitaria, el chileno Luis Almagro haya sido reelegido por otros cinco años como secretario general, con 23 de los 34 votos a favor, en la elección realizada el 20 de marzo. Sn embargo, por todo lo demás, la OEA se ha mantenido en el papel secundario que se esperaba, en buena parte, producto de su limitada naturaleza concertadora, muy similar a la de CELAC. Sea como fuere, más allá de declaraciones políticas (cuasi)insustanciales, se han llevado acciones concretas en el plano estatal, como el apoyo a El Salvador para la gestión del fondo de emergencia solicitado por el coronavirus, o el respaldo a México en un proyecto de digitalización de pymes con vistas a mitigar el posible impacto de la pandemia.

Protagonismo diferente, y mucho más destacado, es el que ha desempeñado la OPS. Ésta, creada en 1902, es la organización internacional de salud pública más antigua del mundo, está inscrita en el marco de la OEA, y, muy posiblemente, ha sido el actor que más ha trabajado en clave regional. Semanalmente, se han elaborado informes y ruedas de prensa, ofreciendo instrumentos regionales de diagnóstico y pronóstico, con apoyo directo a todos los Estados que la conforman.

Se ha encargado de sistematizar y analizar las amenazas de la pandemia, más allá de muertes y contagios, sobre la base de diferentes indicadores, a efectos de ofrecer respuestas, en clave de eficiencia, para los diferentes países. Esto es, explicando de qué manera afecta al virus al continente, identificando lecciones aprendidas y buenas prácticas, o alertando de lugares con funcionamiento exitoso, áreas de preocupación y contextos hacia los que dirigir mayor atención. De hecho, debe destacarse cómo la OPS ha trabajado de manera próxima con las autoridades de cada país, a efectos de entender las particularidades de los diferentes escenarios y dada la profunda heterogeneidad de los contextos epidemiológicos concurrentes (OPS, 2020). Por ejemplo, en Haití, directamente se ha colaborado con las autori- 
dades y el personal sanitario local a efectos de capacitar y formar sobre la manera en cómo realizar pruebas o atender a pacientes con COVID-19. Finalmente, debe destacarse el enfoque regional que siempre ha primado en los lineamientos ofrecidos por la OPS, y que muestran cómo, lejos de ser excluyentes, las escalas geográficas de lo regional, lo estatal y lo local, pueden resultar perfectamente armonizables. Todo, aun cuando no dejar de resultar llamativo que haya sido un organismo interamericano el que se haya erigido como mayor defensor de esta perspectiva regional.

\section{Conclusiones}

América Latina afronta esta situación de alerta sanitaria con una arquitectura regional muy endeble y sin mecanismos colectivos que permitan desarrollar respuestas comunes, mínimamente articuladas, frente a la pandemia. El recurso nacionalestatal ha primado con mayor vehemencia que en Europa, y la heterogeneidad de respuestas ha gravitado desde confinamientos severos hasta posiciones de relativa incredulidad con respecto al alcance de la pandemia.

Los problemas estructurales de la región, como pueden ser la pobreza, la falta de recursos, o la debilidad institucional de buena parte de los aparatos estatales, no pueden ser resueltos con una simple agenda securitaria. De esta forma, las medidas de prevención y la prioridad social del Estado son los únicos aspectos que pueden paliar el impacto de la COVID-19 sobre los sectores más desfavorecidos.

Al respecto, y como han podido dar cuenta estas páginas, para todo lo anterior resulta necesaria una escala regional que, igualmente, debe ser tenida en consideración. Un nivel de actuación supranacional que, sin embargo, se entiende en la mayoría de los casos como irrelevante cuando no como excluyente de los intereses políticos y sociales de la agenda estatal latinoamericana. No obstante, si bien la COVID-19 ha puesto en evidencia la desestructuración regional de América Latina, igualmente puede servir de acicate para encontrar una razón adicional que fundamente de por qué es necesario un entramado regional mucho más sólido que el actualmente inexistente.

Las prácticas regionales neoliberales, desarrolladas bajo el regionalismo abierto, tienen su interés y relevancia en aspectos que, mayormente, transitan por vías diferentes a las que demanda, por ejemplo, la actual alerta sanitaria. De esto dan buena cuenta las experiencias de la Comunidad Andina, la Alianza del Pacífico o Mercosur, de manera que sólo el proyecto centroamericano, con una mirada más amplia y un acervo regional más profundo, representa una relativa excepción.

El regionalismo posliberal está al borde de su finalización, especialmente, como muestran ALBA y UNASUR, y CELAC, como escenario de concertación, apenas está en disposición de proponer unos mínimos insuficientes de convergencia regional. La OEA representa algo parecido, en clave interamericana, aunque no deja de ser significativo que, finalmente, haya sido la OPS, circunscrita al ámbito estrictamente sanitario, y con iguales tintes interamericanos, el organismo que más haya planteado y defendido el recurso regional frente a la pandemia.

No queda lugar al optimismo, pues las variables que explican esta situación ya han sido expuestas en estas páginas: recelo frente a la supranacionalidad, ideologización de las relaciones regionales, obcecación por cuestiones estrictamente co- 
merciales o yuxtaposición de intereses encontrados. La COVID-19, a lo sumo, servirá para poner de manifiesto la debilidad geopolítica del continente como región, su fracturación interna y la ausencia, aun con todo un universo de necesidades, amenazas e intereses compartidos, de un esfuerzo de convergencia regional que hoy por hoy queda tan endeble como lejano.

\section{Referencias}

Acosta, J. (2006). La desintegración andina. Nueva Sociedad, (204), 4-13.

Allen, J. et al. (2020). How the World Will Look After the Coronavirus Pandemic. Foreign Policy. Recuperado de https://foreignpolicy.com/2020/03/20/world-order-aftercoroanvirus-pandemic/

Baldwin, R., y Wecer, B. (2020). Mitigating the COVID Economic Crisis: Act Fast and Do Whatever It Takes. Londres: Centre for Economic Policy Research.

Beck, U. (1993). Risk Society: Towards a New Modernity. Londres: SAGE.

Cairo, H. (2013). Espacio y política: por una teoría política situada. Dados, 56(4), 769-802.

Cairo, H. (2018). Las guerras "virtuosas" de George W. Bush: las transformaciones del territorio, de la soberanía y de los discursos geopolíticos en el siglo XXI. Madrid: Trama.

Cairo, H., y Ríos, J. (2018). América Latina: las incertidumbres de las nuevas integraciones latinoamericanas más abiertas al mundo. En J. Preciado (Coord.), Dimensiones, estrategias y alternativas de la integración autónoma para América Latina y el Caribe (pp.223-254). Guadalajara: Universidad de Guadalajara.

Cairo, H., y Ríos, J. (2020). Geopolítica crítica de la seguridad y la defensa en América Latina (1960-2020). Pensamiento propio, (51). En prensa.

Cambio 21. (2020). ¿Piñera culpa a los inmigrantes por el coronavirus? La polémica y grave frase del presidente: "Queremos agradecer a las FFAA que han protegido las fronteras para que los inmigrantes no traigan la infección del Covid-19”. Cambio 21, 11 de abril. Recuperado de https://cambio21.cl/politica/piera-culpa-a-los-inmigrantes-por-elcoronavirus-la-polmica-y-grave-frase-del-presidente-queremos-agradecer-a-las-ffaaque-han-protegido-las-fronteras-para-que-los-inmigrantes-no-traigan-la-infeccin-delcovid-19-ver-video-5e922e6caa2d741c9940e904

CEPAL. Comisión Económica para América Latina. (2020a). Panorama Social de América Latina 2020. Santiago de Chile: Naciones Unidas.

CEPAL. Comisión Económica para América Latina. (2020b). América Latina y el Caribe ante la pandemia del COVID-19: efectos económicos y sociales. Santiago de Chile: Naciones Unidas.

Comunidad Andina. (2020). Declaración de los Ministros de Relaciones Exteriores y de Comercio Exterior de la Comunidad Andina respecto a la propagación del coronavirus. Comunidad Andina, 8 de abril. Recuperado de http://www.comunidadandina.org/Prensa.aspx?id=12200\&accion=detalle\&cat=NP\&titl $\mathrm{e}=$ secretario-general-de-la-comunidad-andina-debemos-sumar-esfuerzos-para-enfrentarefectos-del-covid19

Da Motta, P., y Ríos, S. (2007). O Regionalismo pós-liberal na América do Sul: origens, iniciativas e dilemas (Serie Comercio Internacional, 62). Santiago de Chile: CEPAL. 
Díaz Galán, E. (2015). La Alianza del Pacífico: características y dimensiones de un nuevo proceso de integración en América Latina. Revista Electrónica Iberoamericana, 9(2), 120.

Flynn, B. (2020). The Inexorable Rise of the Pandemic State? Second-Guessing the longterm political repercussions of COVID 19. Irish Politics Forum, 18 de marzo. Recuperado de https://politicalreform.ie/2020/03/18/the-inexorable-rise-of-the-pandemicstate-second-guessing-the-long-term-political-repercussions-of-covid-19/

Freedom House. (2020). Freedom in the World 2020. Washington D. C.

Gilbert, M. et al. (2020). Preparedness and vulnerability of African countries against importations of COVID-19: a modelling study. The Lancet, 395(10227), 871-877.

Guerra-Borges, A. (2004). América Latina: regionalizar la globalización. De la trayectoria histórica a la utopía convocante. Economía UNAM, 1(2), 110-126.

Hirst, P., y Thompson, G. (1999). Globalization in Question: The International Economy and the Possibilities of Governance. Cambridge: Polity Press.

Hoogevelt, A. (1997). Globalization and the Postcolonial World. Basingstoke: Springer.

Infobae. (2020). "Yo les digo cuándo no": la polémica invitación de López Obrador a mantener actividades pese a coronavirus. Infobae, 23 de marzo. Recuperado de https://www.infobae.com/america/mexico/2020/03/23/yo-les-digo-cuando-no-lainvitacion-de-amlo-a-no-dejar-de-salir-a-pesar-de-la-emergencia-sanitaria-porcornavirus/

International Transparency. (2020). Corruption Perception Index 2019. Berlín. Recuperado de https://www.transparency.org/cpi2019

Malamud, C. (2009). La crisis de la integración se juega en casa. Nueva Sociedad, (219), 97-112.

Malamud, C., y Núñez, R. (2020). La crisis del coronavirus en América Latina: un incremento del presidencialismo sin red de seguridad. Análisis Real Instituto Elcano, (34), 112.

Mann, M. (2002). La globalización y el 11 de septiembre. New Left Review, (12), 5-26.

Marsh, D. et al. (2006). Globalization and the State. En C. Hay et al. (Eds.), The State. Theories and Issues (pp.172-189). Basingstoke: Palgrave Macmillan.

Maxwell, D. et al. (2020). "The Art of War" in the Era of Coronavirus Disease 2019. Clinical Infectious Diseases, (229). En prensa.

McKibbin, W., y Fernando, R. (2020). The Global Macroeconomic Impacts of COVID-19: Seven Scenarios. (CAMA Working Paper, 19).

Mercosur. (2020). Declaración de los presidentes del Mercosur sobre coordinación regional para la contención y mitigación del coronavirus y su impacto. Mercosur, 18 de marzo. Recuperado de https://www.mercosur.int/los-presidentes-del-mercosur-acuerdanmedidas-contra-el-coronavirus/

Ohmae, K. (2005). The next global stage: challenges and opportunities in our borderless world. Nueva Jersey: Wharton School Publishing.

OPS. Organización Panamericana de Salud. (2017). Financiamiento de la salud en las Américas. Washington D. C.: OPS.

OPS. Organización Panamericana de Salud. (2020). Rueda de prensa semanal de la Directora de la OPS. OPS, 5 de mayo. Recuperado de https://www.paho.org/es/documentos/rueda-prensa-semanal-sobre-covid-19-palabrasapertura-directora-5-mayo-2020 
Público. (2020). Bolsonaro llama "gripecita" al coronavirus y descarta el confinamiento. Público, 25 de marzo. Recuperado de https://www.publico.es/politica/coronavirusbrasil-bolsonaro-califica-coronavirus-gripecita-no-ve-necesidad-confinamiento.html

Reich, R. (1991). The Work of Nations: Preparing Ourselves for the 21st Century of Capitalism. Nueva York: Knopf.

Ríos, J. (2011). UNASUR o la Confluencia de dos liderazgos regionales de signo dispar: Brasil y Venezuela. Reflexión Política, 13(25), 50-63.

Ríos, J. (2013). De la cumbre ALC-UE de Madrid a la cumbre CELAC-UE de Santiago de Chile. Expectativas de una asociación estratégica birregional. Revista Oasis, (18), 7594.

Ríos, J. (2020). Una aproximación (geo)politológica a la crisis de la COVID-19 en América Latina. Journal of Latin American Geography, 19(2), 1-8.

Ríos, J. (2017). La Unión de Naciones Suramericanas y la Alianza Bolivariana para los Pueblos de Nuestra América: ¿otra década perdida? Revista de Relaciones Internacionales, Estrategia y Seguridad, 12(2), 111-131.

Rugman, A. (2000). The End of Globalization. Nueva York: Random House.

Sanahuja, J. A. (2013). La Unión Europea y el regionalismo latinoamericano. Investigación y Desarrollo, 21(1), 156-184.

Secretaría General de la Comunidad Andina. (2020). Nota de prensa. Secretaría General de la Comunidad Andina, 13 de abril. Recuperado de http://www.comunidadandina.org/Prensa.aspx $\mathrm{id}=12200 \&$ accion=detalle\&cat=NP\&titl $\mathrm{e}=$ secretario-general-de-la-comunidad-andina-debemos-sumar-esfuerzos-para-enfrentarefectos-del-covid19

Serbin, A. (2009). América del Sur en un mundo multipolar: ¿es la UNASUR la alternativa? Nueva Sociedad, (219), 145-156.

SICA. Sistema de Integración Centroamericano. (2020). Reunión extraordinaria de Jefes de Estado y de Gobierno ante la pandemia del COVID-19. SICA, 12 de marzo. Recuperado de https://www.sica.int/coronavirus

Taylor, P. y Flint, C. (2006). Political Geography: World-economy, Nation-state and Locality. Upper Saddle River, NJ: Prentice Hall. 